\title{
Flyrocks - Detection and Mitigation at Construction Site in Blasting Operation
}

\author{
A. K. Mishra*, M.Rout \\ Department of Mining Engineering, Indian School of Mines, Dhanbad
}

\begin{abstract}
Construction and mining industry spends heavy coins on blasting technology, explosives and their safe detonation, from India's perspective safe blasting holds even more important stand. In India, around $90 \%$ of production comes from surface mines. In any surface mine, blasting is a crucial operation. Explosives in large quantities has been used for fragmentation of rock in surface mines but only a part of the explosive energy has been used in doing the useful work, the rest has been consumed toward unwanted work such as ground vibration, fly rocks, noise and air blast. These blasting practices provide quick, efficient and cheap over-burden removal compared to other processes. However, they are major sources of mine related injuries and accidents. Usually blasting related injuries are related to fly rocks, lack of blast area security, premature blast and misfire. Out of these, fly rocks and lack of security accounts for $68 \%$ of total injuries incurred by blasting practices. The blasting is required for fragmentation and displacement of the broken rock. Fragmented rock is not expected to travel beyond the limit of blast area or the desired throw. However, sometimes they do. These rocks travelling beyond blast area or the throw due to force of explosion is known as fly rock. As fly rock is a critical issue in mining and construction industry, hence it becomes more so important to learn the causes for generation of flyrock and the mitigation measures. This paper deals with causes of fly rock, hazards associated with flyrock and precautions to be taken to control them with the help of a case study at a construction site. The Flyrock accident can be averted by sticking to basic principles of primary as well as secondary blasting. The shock tube initiation system may be preferred over detonating cord. Further, supervision of blast hole charging should get high order preference and care.
\end{abstract}

Keywords Flyrock, Blasting Hazard, Surface Blasting, Construction Blasting

\section{Introduction}

In any surface mines, blasting operation plays a vital role. Commensurate with the increasing production from surface mines; the explosive demand is also on the rise. The explosives demand by the mining sector has risen from 153 thousand tonnes in 1989-90 to 450 thousand tonnes in 2010, which consumes around $80 \%$ of total explosives produced in the country. On the surface mine benches, when any blasting activities are carried out, rock gets fragmented in such a way that the fragmented material is moved forward to make easier mucking of the fragmented mass with reduced cost (Little, 2007). During such blasting process, unexpectedly some stone can get torn and travel to very large distances in addition to this desirable displacement of rock fragments, which is termed as 'fly rock'. This unanticipated fly rock is hazardous to men and machineries which

* Corresponding author:

arvmishra@yahoo.com (A. K. Mishra)

Published online at http://journal.sapub.org/env

Copyright (C) 2011 Scientific \& Academic Publishing. All Rights Reserved are employed in the mine and also to the surrounding environment, therefore, the blasting engineer should take appropriate measures to control them on the field, (Lundborg, et al 1975).This paper discusses the causes and control of fly rock in detailed manner.

In general, there are two kind of movements associated with bench blasting in open cast mines. Initially, there is forward movement of entire rock mass in the horizontal direction which depends on specific charge and secondly on fly rock (Bhandari, 1984), Mishra and Gupta, (2002) and (Bajpayee et. al., 2004). Fly rock is a rock or stone that is propelled beyond the blast area by the force of explosion. Generally our blasts are expected to generate some amount of fly rock but it is the distance of travel which makes huge difference on its impact on surrounding environment.

BLAST SITE

A study of blasting accidents has revealed that more than $40 \%$ of fatal and $20 \%$ of serious accidents resulting from blasting occur due to fly rock, Mishra, (2003).

Each mining operation has a normal fly rock range that can be evaluated, based on blasting experience, available mathematics and software, the blasting area radius is established as some distance greater than the normal. There are 
certain mitigation measures discussed to control this abnormal distance travel of flyrock.

Most of flyrocks fall in the region that forms a semi-circle in front of the face, Ludwiczak, (1985). These flyrock impacts cause craters or blownouts on the surface of bench. The direction of fly is difficult to predict and depends on local conditions and blasting parameters.

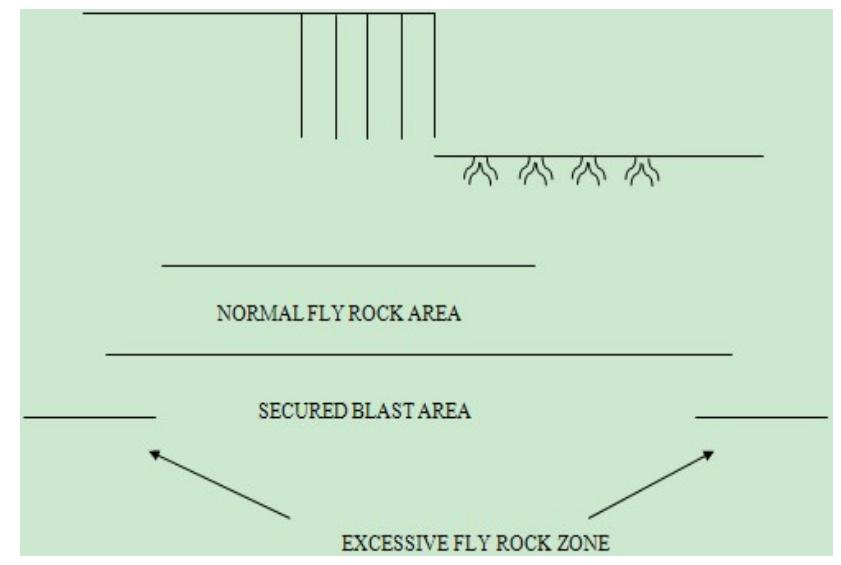

Figure 1. The excessive fly rock zone in surface blasting

\section{Calculation for Normal Fly Rock Zone}

1. Calculation of throw distance and initial velocity of rock fragments can be done with the help of few empirical formulae derived for granite blast, Raina, et al (2007).

However, these formulae hold good for granite only. Hence a more general form is still to be derived.

Also, there is a probability that some flyrock will be thrown a longer distance.

2. Gurney developed a model to describe the expansion of a metal cylinder driven by the detonation of explosive. The model closely predicts the initial vel. of the fragment produced by break-up of cylinder

However, determining the initial velocity of fragment throw and maximum range of fly rock was of no use in solving our problems which are:

a) Demarcating risk zone.

b) Defining blast area.

c) Calculation of risk analytical method (probabilistic approach).

\section{Calculation of Risk}

With the advent of high speed digital video camera we can find the ejection angle of fly rock with initial velocity of fly rock ejection. The computer code can find the probable distance of travel and the point of strike at ground. This enables to find the cause and distance travelled by fly rock which can be used to find the risk associated with the blasting at studied mine site.

\subsection{Causes of Flyrock}

Fly rock in open pit mine blasting usually means that it is unexpected projection of rock mass from blasting beyond blast area. Blast area is an area in which shock wave, flying material or gases from an explosive may cause injury to person. There are numerous factors which determine the blast area:

Geology or material to be blasted

Blast pattern

Burden, depth, diameter and angle of hole.

Blasting experience of mining personnel.

Delay system, powder factor and pounds per delay.

Type and amount of explosive material.

Type and amount of stemming.

Generally fly rocks are caused due to mis-match of explosive energy with the geo-mechanical strength of the rock mass surrounding the explosive charge.

Factors responsible for such mis-match are discussed below:

A. Burden: An insufficient burden is a primary cause of flyrock (Figure 2) from a high wall face. High wall faces are irregular and therefore do not provide uniform burden form each point of the loaded borehole. Wherever, there will be weak points in the high wall, high pressure gases will try to vent out from such points and pose threat. Blasters need to visually examine and profile high wall face and search for zones of weakness, back break, concavity, unusual jointing and overhang.

Problems related to burden causing flyrock:

1. Too short a distance to the bench slope wastes energy.

2. Too great a burden distance causes improper fracturing of rock, creating oversize boulders and potential of Flyrock for next round.

3. Due to irregularity of bench slope, energy of blast pos4. es hazard at the weakest point of bench.

Any deviation while drilling reduces or increases burden.

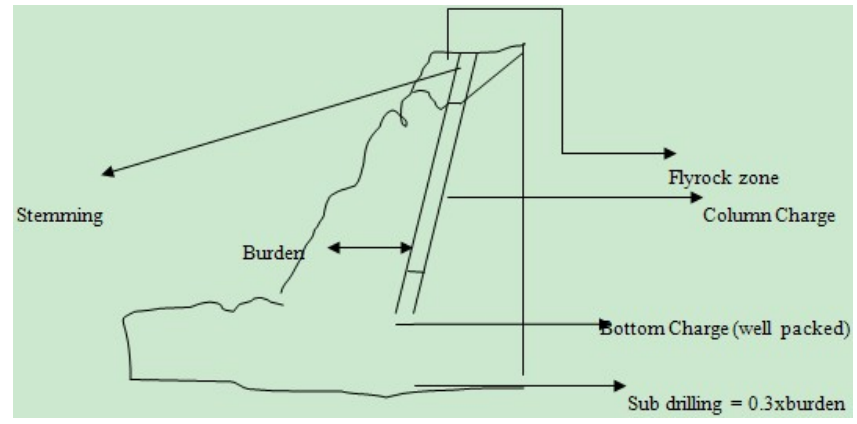

Figure 2. Typical blasting hole in surface mining

B. BLAST HOLE LOADING: Blast hole over charging is one of the frequent causes of the fly rock occurrence. Such overloading generates excessive release of energy. It happens due to loss powder in fissure, joints voids and cracks. In order to prevent overloading, it is necessary to load holes as designed using the correct charge weight.

Additionally, a blast stemming should be sufficiently high to eliminate the possibility of excessive charging and 
holes have to be monitored to check the rise of the explosives.

C. STEMMING: Stemming materials provide confinement and prevent the escape of high pressure gases from blasting holes. This material must be free from rocks and properly tamped. Inadequate stemming results in stemming ejection from the holes resulting in flyrocks. In general, the stemming length should not be less than 25 times the blast hole diameter(Sheridan, 2002). Konya and Walter (1990) recommended length of stemming to be 0.7 times the burden.

D. GEOLOGY AND ROCK STRUCTURE: The rock structure and rock properties vary considerably from location to location even within the same blast area. Problems encountered here are:

1). Discontinuity in geology and rock structure causes a mismatch between explosive energy and resistance of rock.

2). Existence of fissures, joints, weakness and voids are likely to assist in the generation of flyrock.

3) Changing compressive strength, varying abrasiveness and rock density also create hazardous scenario.

The geological features such as mud seams, natural joint or bedding plane fractures, or cavities in the rock can produce more amount of fly rock. Generally, the presence of mud seams and fractures in the rock during the blasting can rapidly vent and accelerate the fragments. In case of cavities and crevices, explosives have been accidentally filled in more quantity while charging for the given amount of burden which results in production of fly rocks for the long distances. The fracturing usually occurs due to back break or over break from earlier blasting. These fractures are becoming the source of flyrock as it can cause dangerous planes of weakness.

E. DETONATOR FINING DELAY: Critical elements of any blast design are firing delays between adjacent holes in a row and also those between successive rows.

1) Burden

2) Spacing

3) Hole depth

4) Rock type

5) Quantity of charge fired per delay

Proper firing delay helps to achieve good fragmentation. Rock fragmented by previous hole must be given chance to move prior to firing the subsequent holes. (Not allowing such delays generates flyrocks).

F. BLASTHOLE PATTERN: Inaccuracies in the design of blasting pattern, including large deviation from planned pattern results in flyrock occurrences. Graphical design of drilling and blasting pattern is performed using 3-D graphics technique. Mines cape by (Mincom, 2004) is an excellent tool for this. The entire drilling and blasting domain can be visualized from different angles thus, forewarning about possible trouble spots before drilling. In most of blasts, excessive amount of fly rock has been generated due to the improper blast design. The causes of improper blast design include:
1) Insufficient explosive confinement

2) Inadequate burden

3) Short stemming region or failure to use stemming

4) High powder factor for the given rock conditions

5) Improper delay between rows

6) Incorrect blast hole delay sequence

7) Inappropriate location of front row holes

8) Top initiation while using the conventional system of detonating fuse

9) Occurrence of misfires during the blasting

G. CARELESSNES: Unfortunately, carelessness in drilling and blasting is a leading cause of excessive fly rock and carelessness during any part of:

1) The blast design

2) The blast hole pattern layout

3) The drilling of the blast holes

4) The loading of explosives

5) The hook-up of the initiation system

H. BLAST SUPERVISION: Generally, the poor blast site control is the major cause of accidents due to fly rock in the surface mines. If the persons in the vicinity of the blast are not removed to a safer place or distance and if they are not prevented from entering in to secured blast area, then fly rock accidents are bound to occur. In some cases, when we are firing the misfired holes, it may result in excessive fly rock due to reduced burden and confinement of the explosive charge.

The following paragraph will discuss a case study of fly rock which occurred at a construction site.

\section{Flyrock Accident Occurred at a Construction Site}

\subsection{Background}

On September 22nd 2010, at 17hr 10minute an incident occurred at working place of Quality Control lab-Cement testing room near the dam site. The boulder formed at the blasting site of power intake of concrete face rock fill dam (CFRD) which was at a distance of $200 \mathrm{~m}$ towards north from the face of dam. The size of the boulder was biotitegniess rock type with dimensions of $3 \mathrm{~m}, 1.5 \mathrm{~m}$ and $1.6 \mathrm{~m}$ in respect of length, breadth and height (Figure 3). For the secondary blasting, the boulder was drilled with two holes of $45 \mathrm{~mm}$ diameter with a spacing of $0.6 \mathrm{~m}$ and depth of $1.5 \mathrm{~m}$. The explosive cartridge of $40 \mathrm{~mm}(390 \mathrm{gm} / \mathrm{cart}$.) and $300 \mathrm{~mm}$ length were used with a detonating cord of $10 \mathrm{~g} / \mathrm{m}$. After the charging of $1560 \mathrm{gm}$ explosive per single hole $0.3 \mathrm{~m}$ was left for stemming. When the blasting occurred a huge sound was heard and two flyrocks ejected from the boulder which covered a distance of $550 \mathrm{~m}$ from the blasting site to the Quality control laboratory (Figure 5). Two persons were working in that testing laboratory where the two flyrocks punctured in the iron sheet roof as well as the underneath card board. Fortunately the two fly rocks fell $3 \mathrm{~m}$ 
apart from the working personnel in that quality control laboratory. The location and effect of flyrock are shown in underneath pictures.

\subsection{Causes of Flyrock Generation}

On investigation of the charging practice and other details, it was observed that

The initiation system was detonating cord, which was used. It is a destructive type of initiative system which might have disturbed the stemming material and would have caused sudden release of detonation gases through the collar of the hole.

The burden from one of the free face (edge) was too less which might have caused the excessive flyrock generation. hole.

Explosive charge was more than optimum in one of the

The blasting crew was not trained and did not have enough knowledge about the consequence of secondary blast.

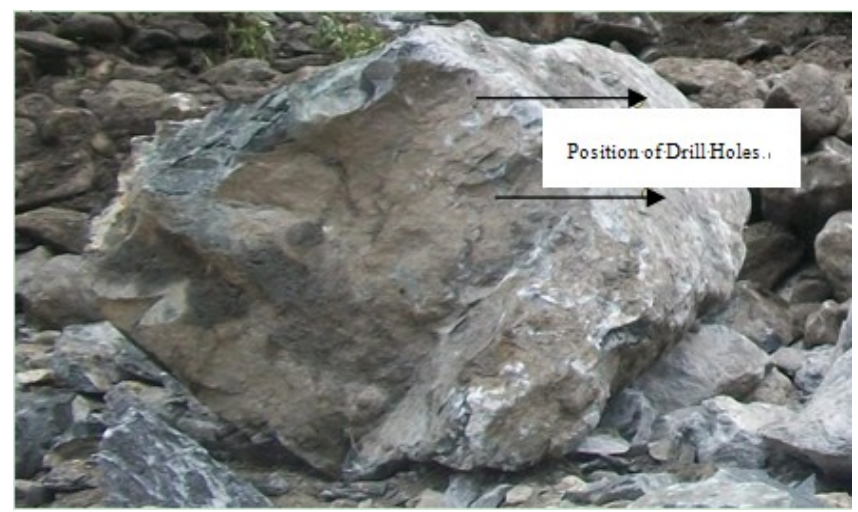

Figure 3. The boulder which was blasted

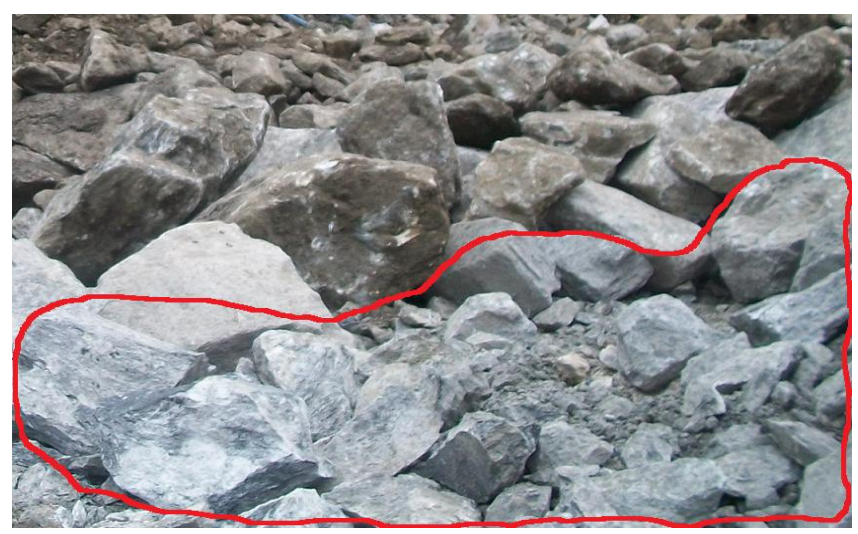

Figure 4. Photograph showing the place after boulder blasting

\subsection{How Could Have We Averted It?}

Probably it was sheer luck which saved two of the persons who were working in the laboratory. If this would have fallen on them, consequences could have been severe.

After the investigation it revealed that if following measures would have been taken then the accident might have be -en averted.
1. Shock tube initiation system would have been used instead of detonating cord.

2. The blasting in charger should have taken personal care to supervise the charging operation.

Training of blasting crew would have been done and an internal certification procedure would have averted the situation.

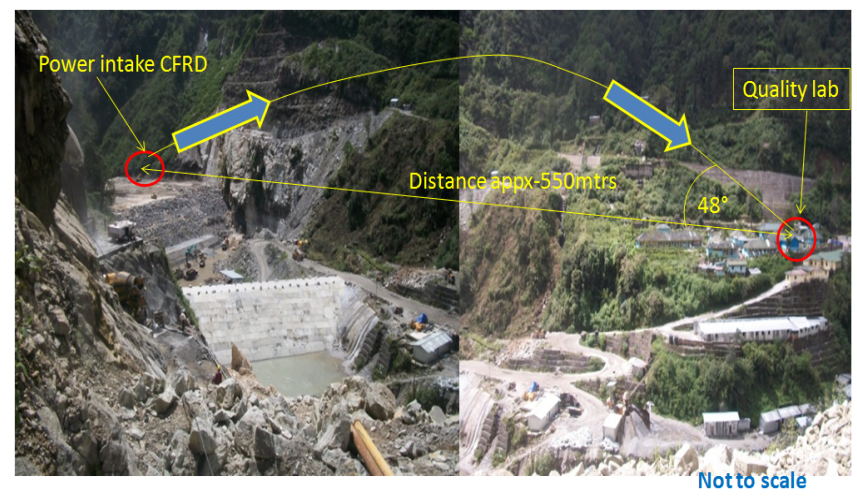

Figure 5. Distance covered by the flyrock

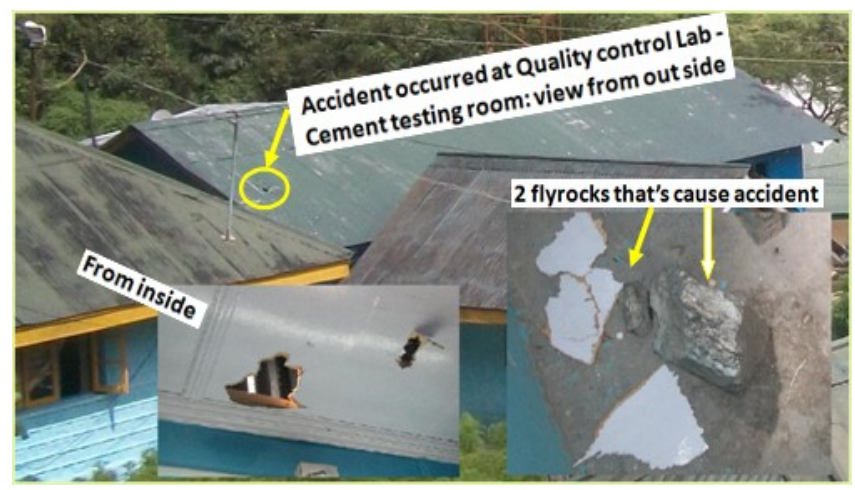

Figure 6. Effect of flyrock to the structures

\section{Conclusions}

Flyrock can occur due to various reasons as discussed in the paper. Mainly fatal accidents have occurred due to fly rock in mines and at construction sites. Even a small mistake can be disastrous for the operating firm engaged in excavation job. The basic fundamentals of primary as well as secondary blasting should always bestick to avoid any unwanted incidence. Safety first should not only be communicated and discussed but should also be followed religiously at work place. Shock tube initiating system should be preferred over detonating cord. Supervision of charging should be done carefully and the blast design should be followed meticulously. Training and refreshment training should be organized on periodic basis to avert any accident at work site.

\section{REFERENCES}


[1] Bajpayee T.S., Rehak T.R., Mowrey G.L., and Ingram D.K., (2004), Blasting injuries in surface mining with emphasis on flyrock and blast area security, Journal of Safety Research, vol. 35 , pp. $47-57$.

[2] Bhandari, S., (1984), Flyrock during blasting operationsControlled environmental hazard, Proceedings of the 2nd National Seminar on Minerals and Ecology, Oxford \& IBH Publishing Co., New Delhi, pp. 279-308.

[3] Fernberg, H.,(2003),Principles of Rock Blasting. Surface Drilling, first ed. Atlas Copco, Sweden, pp. 6-8.

[4] Kecojevic V., Radomsky M.,(2005),Flyrock phenomena and area security in blasting-related accidents, Safety Science, Vol. 43, pp. 739-750.

[5] Konya, C.J., Walter, E.J.,(1990), Surface Blast Design. Prentice Hall Inc., NJ, p. 303.

[6] Little T. N., (2007), Flyrock Risk, EXPLO Conference, Wollongong, NSW, 3 - 4 September, pp. 35-43.

[7] Ludwiczak, James T., (1985), Determining the Blast area, The journal of Explosives Engineering, Vol.-2, No. 2, pp. 20-23.
[8] Lundborg, N., Persson, A., Ladegaard-Pedersen, A., and Holmberg, R., (1975), Keeping the lid on flyrock in open pit blasting, Engineering and Mining Journal, May, pp. 95-100.

[9] Mishra, A. K., and Gupta, R. N., (2002), Design of blast using high resolution camera, Proceedings of 7 th International Symposium on Rock Fragmentation by Blasting(Fragblast-7), Metallurgical Industry Press, Beijijng, pp. 378-389.

[10] Mishra, A. K., (2003), Air Blast and Fly Rock - avoidable Hazards of Blasting, Mining engineer's Journal, Volume-4, No. 12, pp.11-18.

[11] Raina, A. K., Chakraborty, A. K., Choudhury, P. B. and Sinha, A., (2011), Flyrock danger zone demarcation in opencast mines: a risk based approach, Bulletin of Engineering Geology and the Environment, Vol. 70, No. 1, pp 163-172.

[12] Sheridan, R.A., (2002),Precautions against flyrock. Explosives Information Bulletin. Explosives Inspectorate, Safety and Health Administration, Queensland Government, p. 3. 